\title{
MOISE: A pilot experiment towards long term sea-floor geophysical observatories
}

\author{
Barbara Romanowicz ${ }^{1}$, Debra Stakes ${ }^{2}$, Jean Paul Montagner ${ }^{3}$, Pascal Tarits ${ }^{5}$, Robert Uhrhammer ${ }^{1}$, Michael Begnaud ${ }^{2}$, \\ Eleonore Stutzmann ${ }^{3}$, Michael Pasyanos ${ }^{1}$, Jean-Francois Karczewski ${ }^{4}$, Steven Etchemendy ${ }^{2}$, and Douglas Neuhauser ${ }^{1}$ \\ ${ }^{1}$ Seismological Laboratory, U.C. Berkeley, Berkeley, CA, U.S.A. \\ ${ }^{2}$ Monterey Bay Aquarium Research Institute, Moss Landing, CA, U.S.A. \\ ${ }^{3}$ Institut de Physique du Globe, Paris, France \\ ${ }^{4}$ Division Technique, Institut National des Sciences de l'Univers, Paris, France \\ ${ }^{5}$ Université de Bretagne Occidentale, Brest, France
}

(Received May 6, 1998; Revised August 4, 1998; Accepted September 21, 1998)

\begin{abstract}
We describe the scientific purposes and experimental set-up of an international deployment of a 3 component broadband seismometer package on the ocean floor in Monterey Bay which took place during the summer of 1997. Highlights of this experiment were the installation, performed using a remotely operated vehicle (ROV), the underwater connection of the different components of the package, and the successful retrieval of 3 months of broadband seismic and auxiliary data. Examples of recordings of teleseisms and regional earthquakes are presented and the background noise characteristics are discussed, in comparison with those of near-by broadband land sites, current-meter data from the vicinity of the ocean bottom package, as well as pressure data from deeper ocean sites.
\end{abstract}

\section{Introduction}

The need for long term ocean floor observatories for the purpose of solid earth studies has now been widely recognized and several national and international efforts are underway to resolve the challenging technological issues associated with such deployments. In the summer of 1997 , we conducted a pilot, target of opportunity international experiment in Monterey Bay (MOISE, Monterey Bay Ocean Bottom International Seismic Experiment, Romanowicz et al., 1997; Stakes et al., 1997, 1998), associating the resources and expertise of three teams: MBARI (Monterey Bay Aquarium Research Institute), a multi-institutional team from France (IPG Paris; DT/INSU: Division Technique de l'Institut National des Sciences de 1'Univers; Université de Bretagne Occidentale, Brest), and the Seismological Laboratory at UC Berkeley. The primary goal of this experiment was to demonstrate the feasibility of deployment and intermediate term operation of several geophysical packages on the seafloor, using a remotely operated vehicle (ROV). The installation was successful, and 3 months of broadband seismic and various auxiliary data were acquired and processed. In what follows, we briefly describe the background motivation and technical aspects of the MOISE experiment and discuss the resulting broadband seismic data.

\section{Scientific Motivations}

Due to the limited distribution of continents and ocean islands around the world, it has long been recognized that the coverage in land-based seismic and other geophysical observatories is not adequate to address many important scientific issues related to plate tectonics and the deep structure and dy-

Copy right (c) The Society of Geomagnetism and Earth, Planetary and Space Sciences (SGEPSS); The Seismological Society of Japan; The Volcanological Society of Japan; The Geodetic Society of Japan; The Japanese Society for Planetary Sciences. namics of the earth. These have been described in detail in several documents (COSOD II, 1987; Purdy and Dziewonski, 1989; Forsyth et al., 1995; Montagner and Lancelot, 1995 ) and we will only briefly summarize them here.

In spite of significant international efforts to increase the distribution of land-based state-of-the-art broadband seismic stations around the world (i.e. Romanowicz and Dziewonski, 1986), many areas of the southern hemisphere remain poorly sampled for global tomographic studies of the earth's deep mantle. This limits resolution in the distribution of lateral heterogeneity and anisotropy in the upper-mantle and transition zone, and therefore our ability to map the precise geographical distribution of dynamically critical upwellings and downwellings, and, for example, determine the precise nature of the boundary-layer at the $670 \mathrm{~km}$ discontinuity. Likewise, based on studies of specific patches sampled by currently existing data, the D" region has been recognized as the locus of strong lateral heterogeneity and anisotropy. Assessing whether these observations represent a singularity or a general property of D" and constraining their physical nature is critical to our understanding of the dynamics of this crucial boundary layer, yet we are limited by the global distribution of earthquake sources and receivers, even as the pool of continental stations has improved in the last ten years. This results in uneven sampling of D", particularly in the southern hemisphere. Better sampling of the inner core is also needed to improve our understanding of its structure and anisotropy and this necessitates installation of seismic stations at optimal locations with respect to seismic sources (for example, antipodal), and most of these are under water. The sparse distribution of seismic stations in the southern hemisphere also limits the azimuthal sampling of the source radiation in the case of southern earthquakes, and therefore limits our resolution of the corresponding source processes.

At the regional scale, California is in a particularly good 


\section{Western US Broadband network of the future}

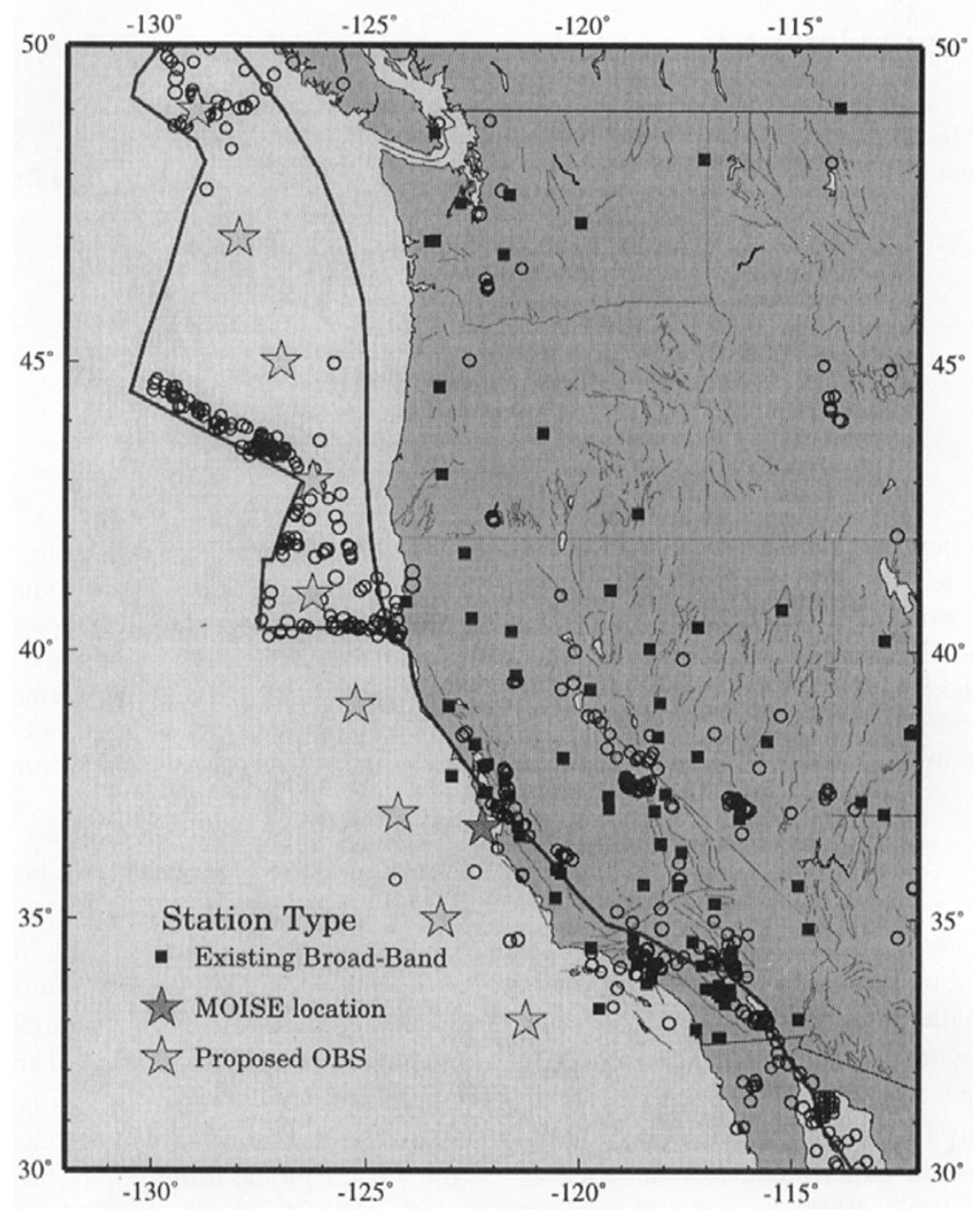

Fig. 1. Current distribution of land-based broadband seismic stations in the western US, and tentative distribution of permanent broadband ocean floor observatories of the future that would complement the land-based network for a more balanced coverage of the western US plate boundaries. Circles indicate seismicity for the time period 1965-1997, with magnitude greater than 5.0.

position to benefit from the installation of off-shore permanent broadband seismic stations, to complement the land based network. Indeed, most of the existing stations are located on the east-side of the north-America/Pacific plate boundary and offer limited azimuthal coverage for moderate to large regional earthquakes on the main active faults (Fig. 1). They also provide limited location and source mechanism resolution for infrequent and generally smaller $(\mathrm{M}<4)$ off-shore earthquakes on faults, such as the San Gregorio, that are known to have experienced significant (M6) events. Finally, off-shore broadband recordings of on-land earthquakes would provide much needed data to constrain the three-dimensional structure of the crust and thereby improve our understanding of the nature and evolution of this plateboundary. Since large regional events are rare, deployment of ocean bottom stations for long periods of time (years) is necessary for this purpose.

There are several technical challenges that need to be addressed before permanent ocean bottom seismic observatories are deployed routinely: issues of optimum installation (borehole versus ocean floor), means of installation (manned or unmanned vehicles), sources of power supply and means of data retrieval are among the most critical ones.

One of the key issues in the design of these ocean bottom observatories is how to optimize installation in order to minimize the background noise in the frequency bands most relevant to the recording of regional and distant earthquakes. Background noise on the sea-floor has been well documented in the frequency band of interest $\left(10^{-3}\right.$ to $\left.10 \mathrm{~Hz}\right)$ from a combination of standard short-period OBS deployments and differential pressure-gauge measurements (e.g. Webb, 1997). Notably, such an experiment was conducted in San Francisco Bay in the late 1960's (Sutton and Barstow, 1990). However, measurements from 3 component broadband seismometers have been few. The main problem is the challenge of installation of broadband seismometers on the ocean floor, since they require precise leveling and centering that is difficult to achieve remotely. In recent years, two experiments successfully retrieved broadband seismic data acquired from modern seismometers, one in the Atlantic ocean (Montagner 
et al., 1994b) and the other in the Japan Sea (Suyehiro et al., 1992). Due to technical difficulties, in both experiments, only several days of ocean bottom data were retrieved, but background noise was successfully measured in the period band 1-3000 s, indicating lower noise on the sea-floor than in the borehole. The issue of whether installation directly on the ocean floor (with partial or complete burial in the sediments) or in boreholes is preferable has not been completely resolved yet and is one of the objectives of the ongoing OSN1 experiment (Orcutt and Stephen, 1993; Purdy, 1995).

MOISE is therefore one among several pilot experiments designed in the spirit advocated by the International Ocean Network program (ION, Suyehiro et al., 1995) as well as the U.S. Ocean Seismic Network program (OSN), and aimed at defining the technology and optimal deployment procedures appropriate for the future installation of permanent ocean bottom geophysical observatories. In spite of high noise levels encountered, the MOISE experiment successfully demonstrated the feasibility of an intermediate term stand-alone deployment on the ocean floor.

\section{Technical Description of MOISE Experiment}

The site of the MBARI experiment was chosen in February 1997, on a flat plateau area called Smooth Ridge in Monterey

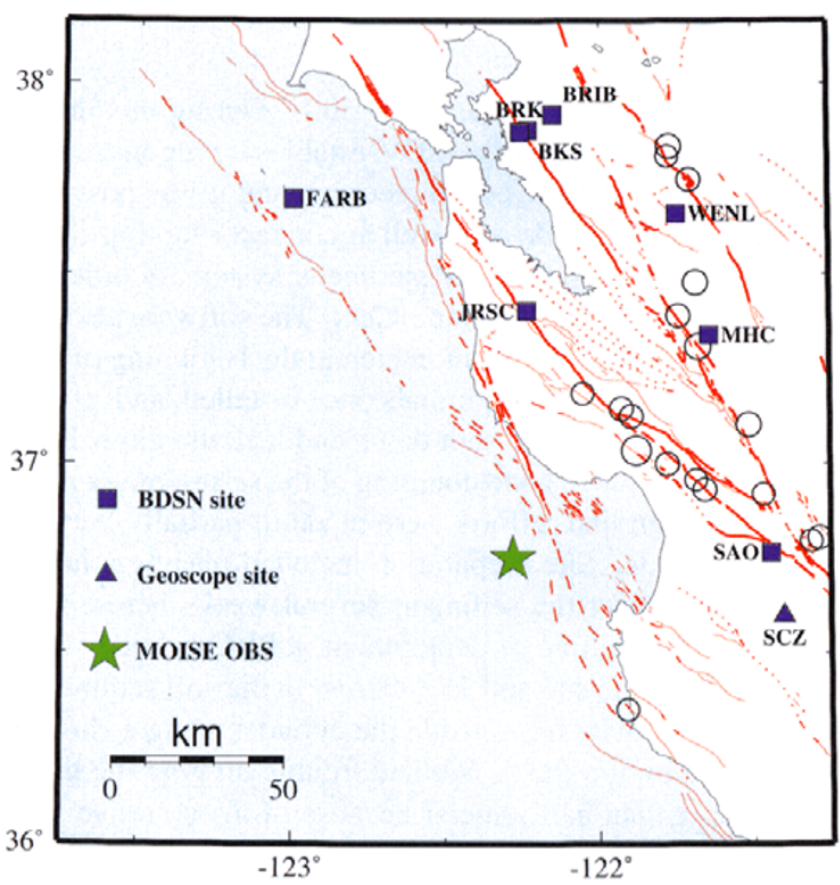

Fig. 2. Location of the MOISE deployment, $40 \mathrm{~km}$ off-shore in Monterey Bay, shown relative to the closest land broadband stations of the Berkeley Digital Seismic Network (BDSN). Station FARB is an island site equipped with a set Guralp CMG40T broadband seismometers. Other stations (JRSC, SAO, MHC) operate Streckeisen STS-1's or STS-2's. Station BKS is located near our central processing site at UC Berkeley in the San Francisco Bay Area. SCZ is a station of the global GEOSCOPE network operated by the French (Romanowicz et al., 1991). Major faults are indicated by thick lines. Broken lines indicate approximate traces of major off-shore faults, such as the San Gregorio fault just East of the MOIS site. Circles indicate seismicity at the level M 5.0 and larger, for the time period 1965-1997.
Bay, just beyond the active San Gregorio fault (Fig. 2), $40 \mathrm{~km}$ off-shore, at a water depth of $1015 \mathrm{~m}$. Smooth Ridge is a sedimented portion of the continental margin that lies between Monterey Canyon and Cabrillo Canyon. The spine of Smooth Ridge is capped with a 200 m wide carbonate pavement and artifacts of mud volcanism, presumably associated with a methane degassing event. The MOISE instruments were installed $200 \mathrm{~m}$ west of the authigenic carbonates. The edges of Smooth Ridge are characterized by slump features, many of which have benthic fauna indicative of lateral fluid flow. The poorly consolidated sediment is likely several hundred meters thick. It has a high organic content but is barren of microfauna and authigenic carbonates. The nature of the basement rocks is uncertain. Samples to the south are likely Monterey Fm (Miocene sediments) but Franciscan sandstones are exposed on the west side of the San Gregorio adjacent to Monterey Peninsula.

At the time of the site selection, the ocean bottom currents were very low, indicating that this location should be optimally "quiet" from the seismic point of view. The deployment of the scientific packages was performed using the MBARI ship "Point Lobos" and the MBARI remotely operated vehicle (ROV) "Ventana", with maximum operating

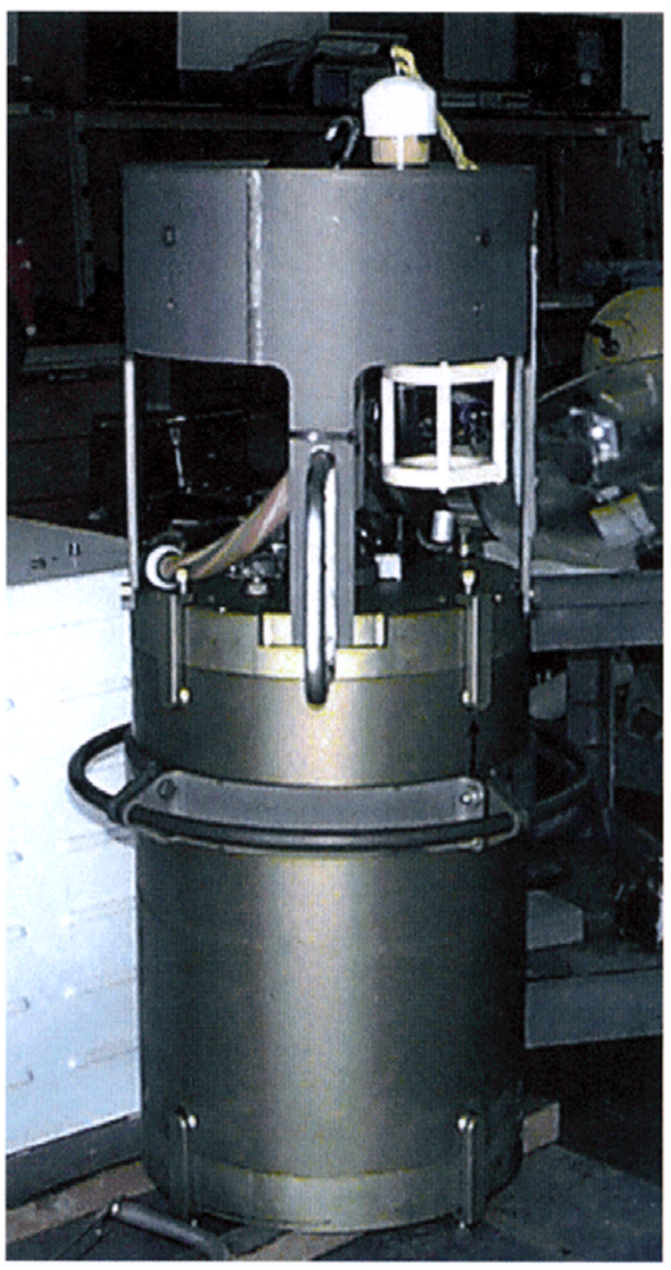

Fig. 3. Photograph of the seismometer package before installation. At the top of the structure is the underwater connector linking the seismometers to the recording system located in its vicinity. 


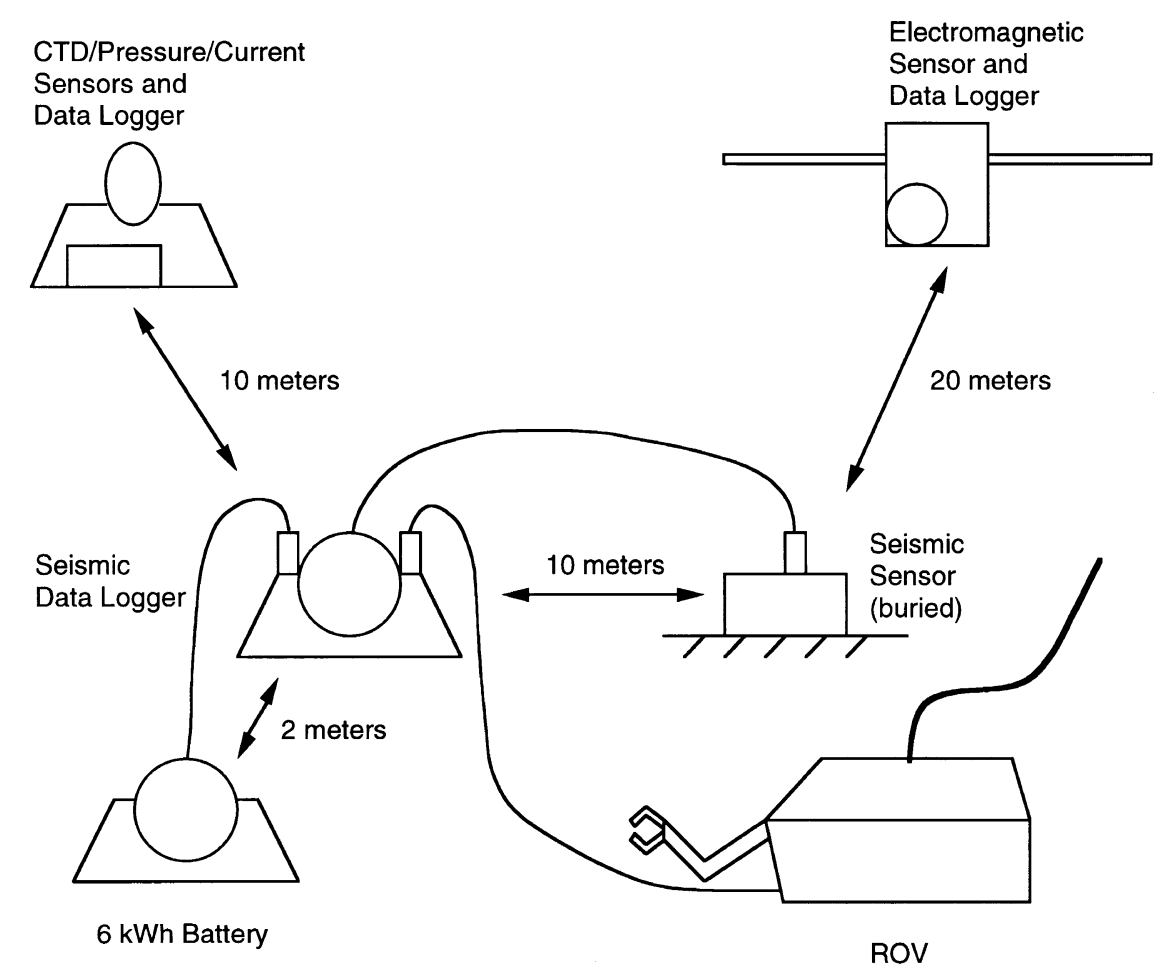

Fig. 4. Block diagram illustrating the experimental set-up on the seafloor. The ROV Ventana is shown connected to the L-Cheapo data logger, which occurred during 3 phases of the experiment: at installation, during a special dive in the middle of the deployment period to check the health of the system and at recovery time, to send clamping commands to the seismometer system.

depth of $1850 \mathrm{~m}$. The location of the experiment was accessible within 2 hours transit time from Moss Landing (CA), the MBARI headquarters.

The central instrument package of MOISE was a 3 component broadband seismic package composed of Guralp CMG3 sensors mounted on leveling gimbals. The electronics were adapted for this ocean floor deployment by DT/INSU. The seismometers had been previously deployed in the midatlantic ocean, during the OFM experiment (Observatoire Fond de Mer, Montagner et al., 1994a,b). The seismic package includes a 16-bit, gain-ranged digitizing system, an automatic re-centering system as well as a self-leveling system driven by a small CPU. The cylindrical aluminum housing was designed by the DT/INSU and outfitted with handles for manipulation by the ROV and the male side of an 8-pin Nautile connector (Fig. 3). During the deployment, the seismic package was connected underwater to a lithium battery package as well as to the recording system. The block-diagram shown in Fig. 4 describes the different components of the MOISE system. The recording system was designed and built by Scripps Institution of Oceanography (SIO) for ocean bottom applications (Low-cost Hardware for Earth Applications and Physical Oceanography, "L-Cheapo", J. Orcutt, personal communication). The L-Cheapo software was modified for the MOISE experiment so that it would allow simultaneous connections to the seismic sensor package and the ship. In this way, it was possible to establish communication with the sensor package directly from the ship, which was done three times: at installation and retrieval time, and, also, one month after installation, to verify the good functioning of the seismometers and data recording. During this intermediate visit to the site, the ROV established a connection from the ship to the L-Cheapo recorder, and it was possible to retrieve samples of data, as well as connect a lap-top computer aboard the ship to the seismometer system, in order to relevel and recenter the seismometers. The software also allowed us to instruct the seismometer, at the beginning of the experiment, to unlock the gimbals once installed, and, at the end of the experiment, to shut down and lock the gimbals.

In order to achieve good coupling of the seismometer system with the ground, efforts were made to partially bury it in the sediments. Site preparation included placing a large weight to compact the sediment several weeks before deployment. At the time of deployment, a PVC cylinder was first brought to the site and $75 \%$ buried in the soft sediment, which was removed from inside the cylinder using a shovel manipulated by the ROV. We had trouble digging the hole much deeper than half a meter because of the cohesive nature of the organic and clay rich sediment. The seismometer package was then lowered into this hole by elevator. The gap left between the seismic package and the PVC cylinder was filled with $3 \mathrm{~mm}$ glass beads to consolidate the installation and allow easy recovery at the end of the experiment. The seismic package had a rather elongated shape (Fig. 3), partly because the underwater connectors were mounted on its top and, once installed, it was protruding about $70 \mathrm{~cm}$ above the sea-floor, thus presenting an unfortunately large surface to the bottom ocean currents.

Difficulties during installation due to unexpected levels of bottom water currents and the hovering position of the rover 
08/21/97 16h11m24.7s

$38.59 \mathrm{~N}-118.5 E \mathrm{~h}=11.14 \mathrm{~km} \mathrm{M}=4.5$
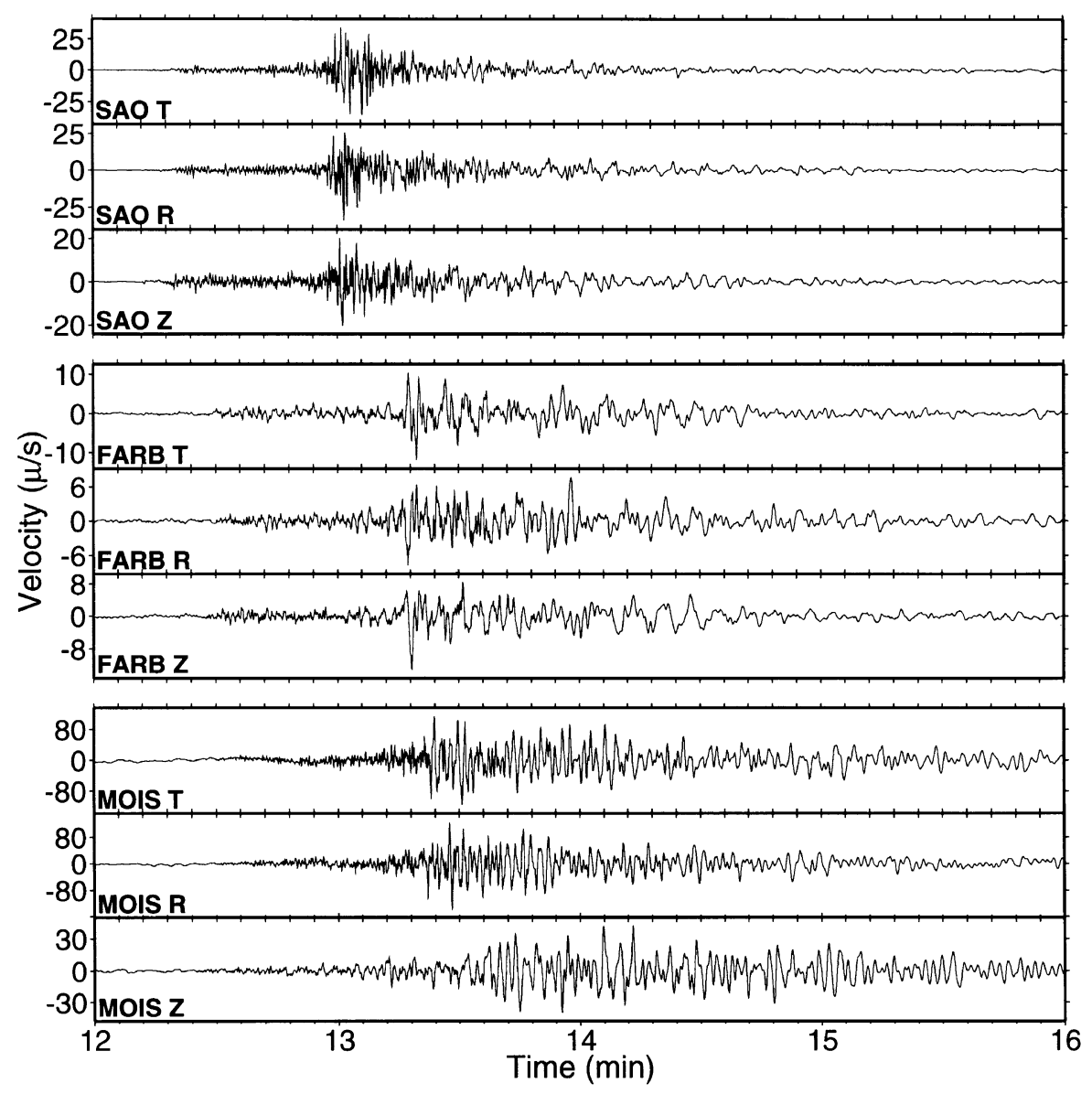

Fig. 5. Example of broadband data for a regional earthquake (Nevada, distance $\sim 400 \mathrm{~km}$ ) recorded at MOIS, a nearby island station, FARB and a nearby continental station, SAO. The data have been high-pass filtered at $50 \mathrm{sec}$.

during the installation of the heavy (100 kg in water) seismic package, prevented the Ventana operators from positioning the package completely vertically and the resulting tilt of the seismometers was near the limit of linearity for the instrument specifications. It also prevented them from installing a transparent "hat" over the package, which had been designed by DT/INSU to shield it from direct action by currents. The most suspenseful part of the installation was the fitting of the underwater connectors between the seismometer and the recording system, accomplished while the Ventana was hovering in strong (up to $20 \mathrm{~cm} / \mathrm{s}$ ) currents. It took 2.5 hours to establish the first connection. The following ones were performed faster, as the Ventana operators gained experience and the dataflow was successfully established, via RS232 connections, first to the ship, and then to the recording system, the latter for the 3 months duration of the experiment.

In addition, a CTD/pressure gauge (on loan from Curt Collins at the Naval Postgraduate School), with a support frame and anchor, as well as an S4 current meter, were deployed on a short mooring in the vicinity of the seismic package for the entire duration of the experiment. These were stand-alone instruments. In particular, the current meter data proved invaluable in understanding the sources of seismic background noise during this deployment. A selfcontained electromagnetic package containing magnetometers, electrometers and an internal data logger designed at UBO (Montagner et al., 1997) was deployed at the same site during the same time period. The resulting data will be described in a separate publication. Finally, several other instruments were deployed in Monterey Bay during the same time, as part of a separate experiment (MBARI Margin seismology project): 3 standard three channel $4.5 \mathrm{~Hz}$ OBS's and a single channel hydrophone with an independent L-Cheapo recorder, to monitor microseismic activity of the San Gregorio and Monterey Bay Fault zones.

\section{Seismic Data Analysis and Results}

Three component broadband seismic data were acquired continuously on the ocean floor from 06/21/97 through $09 / 11 / 97$, at a sampling rate of $20 \mathrm{samples} / \mathrm{sec}$. Several regional earthquakes of magnitude 3.5 and larger as well as several large teleseisms were well recorded during that time period. Comparison of the records obtained at the oceanbottom site (station name: MOIS) with those of near-by land sites of the Berkeley Digital Seismic Network (BDSN) and of the Geoscope Network (SCZ) provide useful insight into 
Venezuela 07/09/97 9:24 Ms=6.8 delta=60 deg

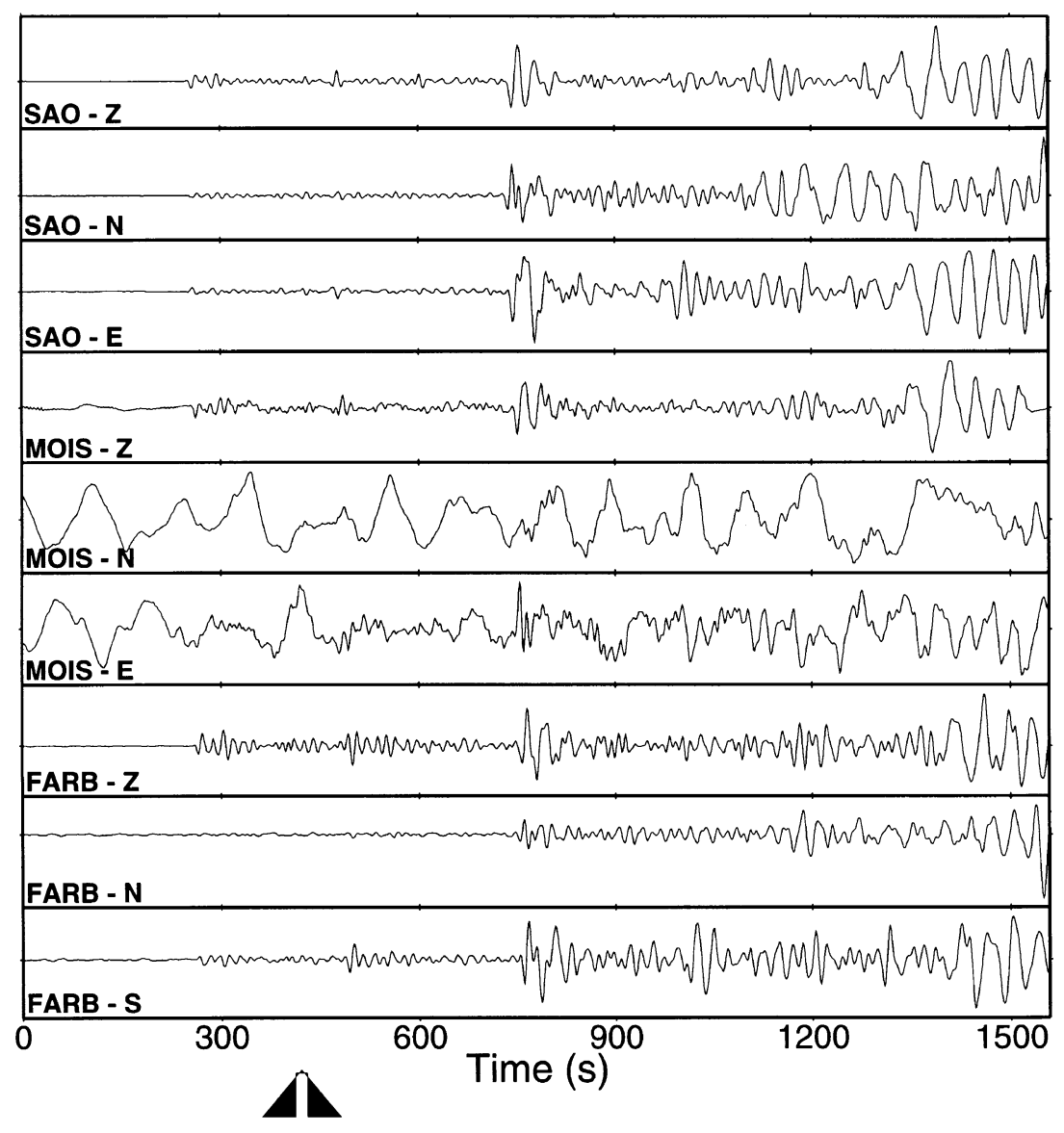

Fig. 6. Example of data for a teleseism for the same stations as in Fig. 5. Note the clear recording of body and surface waves on the vertical component of MOIS. Data were filtered between periods of 5 and $60 \mathrm{sec}$.

the quality of the data. Figures 5 and 6 show examples of recordings at MOIS of a regional and a teleseismic event respectively, compared to those of BDSN station FARB, a noisy island site (Fig. 2), as well as SAO, the closest BDSN continental site. The regional event data are raw, but the teleseismic ones were band-pass filtered between 5 and $50 \mathrm{sec}$, a frequency band of minimum noise (or low-noise "notch") as documented from previous ocean-bottom experiments (e.g. Webb et al., 1991; Montagner et al., 1994a,b). Background noise levels were found to fluctuate considerably in this period band and, not surprisingly, the best recordings were obtained during the quietest periods, when noise in the minimum noise window was comparable to that observed commonly at nearby land sites. In Fig. 6, we note that the P wave and its multiples as well as the $\mathrm{S}$ wave and Rayleigh waves are well recorded on the vertical component of MOIS. The S wave and Rayleigh waves are visible on the east component but the north component is particularly noisy during this time interval.

Figure 7(a) presents a comparison of noise spectra recorded at MOIS at different times during the same day $(08 / 18 / 97)$. At periods shorter than $10 \mathrm{sec}$, the noise is relatively stable for this time period, however, it presents large fluctuations at longer periods, in particular in the "low-nois notch", where it spans $30 \mathrm{~dB}$ over less than 12 hours, on all three components. Figure 7(b) presents a comparison of noise recorded simultaneously at MOIS, the island station FARB and the continental station SAO. Below $10 \mathrm{sec}$, the continental site is by far the quietest and noise levels at MOIS and FARB are comparable on the vertical component. The microseismic peak is somewhat wider at MOIS and FARB than at SAO, and has much larger amplitude at MOIS, although not exceeding much the high noise model values of Peterson (1993). For MOIS, noise decreases rapidly at higher frequencies, and, at $0.2 \mathrm{~Hz}$, reaches levels comparable to those at SAO and FARB. At periods longer than $5 \mathrm{sec}$, the "low-noise notch" is particularly prominent on the vertical component of MOIS. Beyond 30-50 sec, and in contrast to the land stations, noise at MOIS increases rapidly on all three components and exceeds the levels of the high noise model. In the case of land stations, noise fluctuations at low frequencies have been documented to be related to atmospheric pressure fluctuations, particularly on the horizontal components. On the ocean floor, as documented from pressure measurements, noise in the "low-noise notch" is known to fluctuate with bottom current velocity (e.g. Webb et al., 1991).

Investigation of the source of the large noise fluctuations at station MOIS in the low-noise window was made possible owing to the simultaneous recording of auxiliary data. In 


\section{MOIS Power Spectral Density - 08/18/1997}

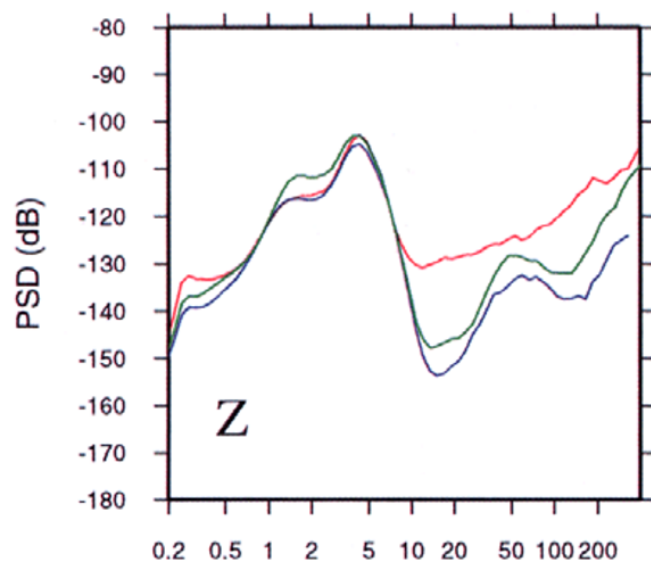

Period (sec)

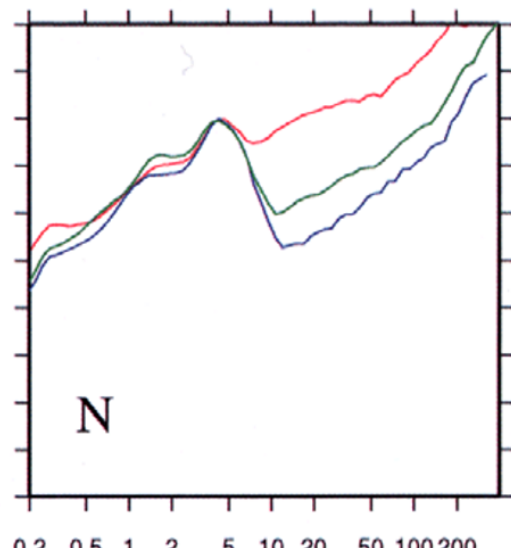

Period (sec)

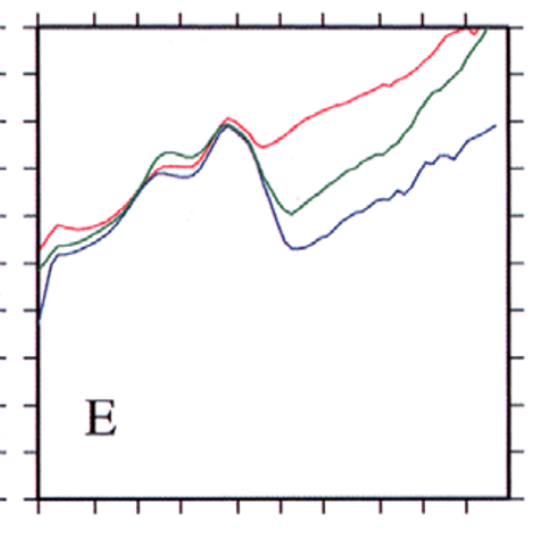

Period (sec)

(a)

\section{Power Spectral Density - 08/18/1997 - 20:00 hours}

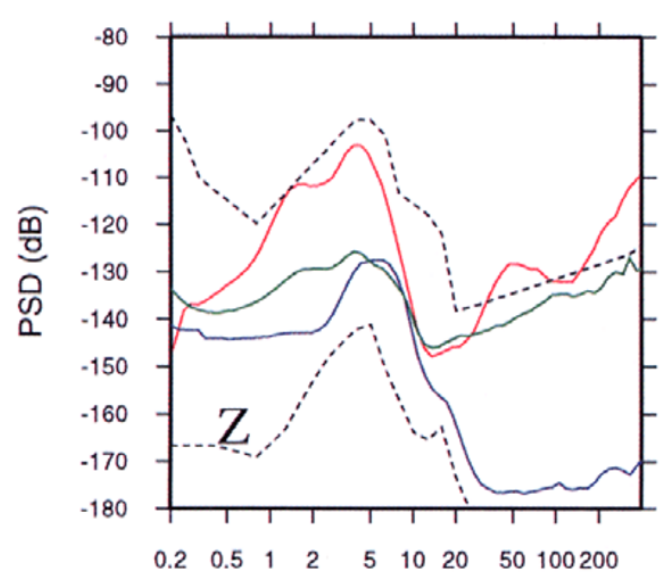

Period (sec)

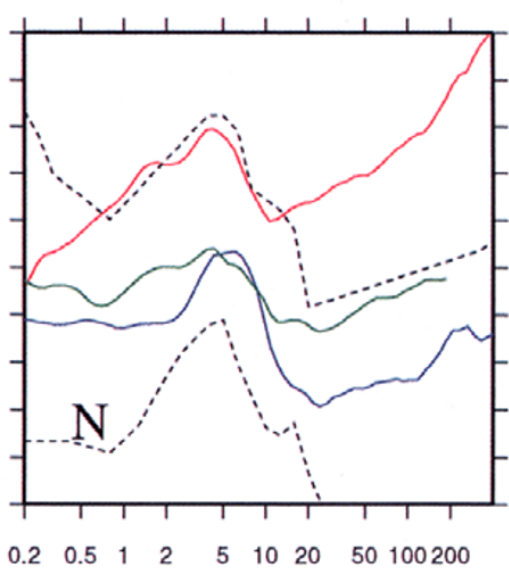

Period (sec)

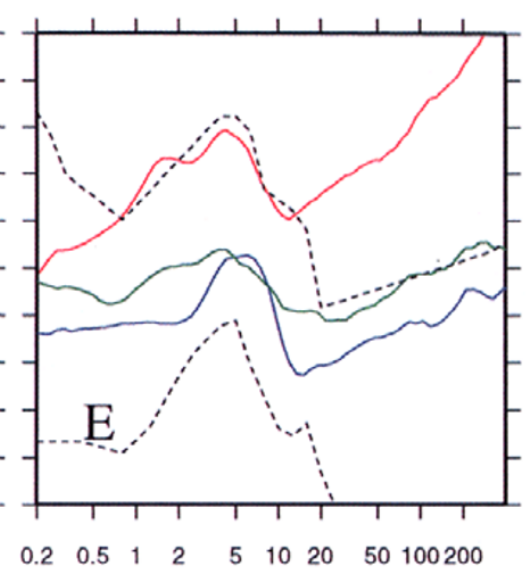

Period (sec)

(b)

Fig. 7. (a) Comparison of noise spectra at ocean bottom station MOIS, computed using 1 hour of data successively starting at 12:35 (red), 16:35 (green), 20:35 (blue) UTC on a day free of significant earthquakes (08/18/97). Columns 1-3 show noise on the vertical (Z), North (N) and East (E) components respectively. (b) Comparison of noise levels registered over a one hour period on the same day at MOIS (red), FARB (green) and SAO (blue). Broken lines indicate the high and low noise model of Peterson (1993).

Fig. 8, we present the fluctuations of current velocity and seismic noise over a period of 24 hours, on a seismically quiet day $(09 / 01 / 97)$. The variation with time of the theoretical solid tide at the MOIS location is also given for reference. As Fig. 8 illustrates, in the period band 10-50 sec, background seismic noise is often strongly correlated with the bottom current velocity, which exhibits large fluctuations that can in general be related to tides. Figure 9 shows a similar plot on a day when the correlation was poorer, due primarily to the occurrence of a teleseism (Western Australia, Ms 6.0; origin time 09:20 UTC). This increased the levels of power spectral density in the seismic signal during a time when the current velocity happened to be low.

The current strength turned out to be unexpectedly high during the summer at the MOISE site, a situation which prevailed for the entire duration of the experiment and which has been attributed, at least partly, to the presence of the El Niño phenomenon. The strong influence of bottom currents on the background seismic noise is easily explained by the experimental set-up, with the tilted seismic package protruding significantly above the sea-floor. On the other hand, during quiet periods, the background noise between 10-30 sec 


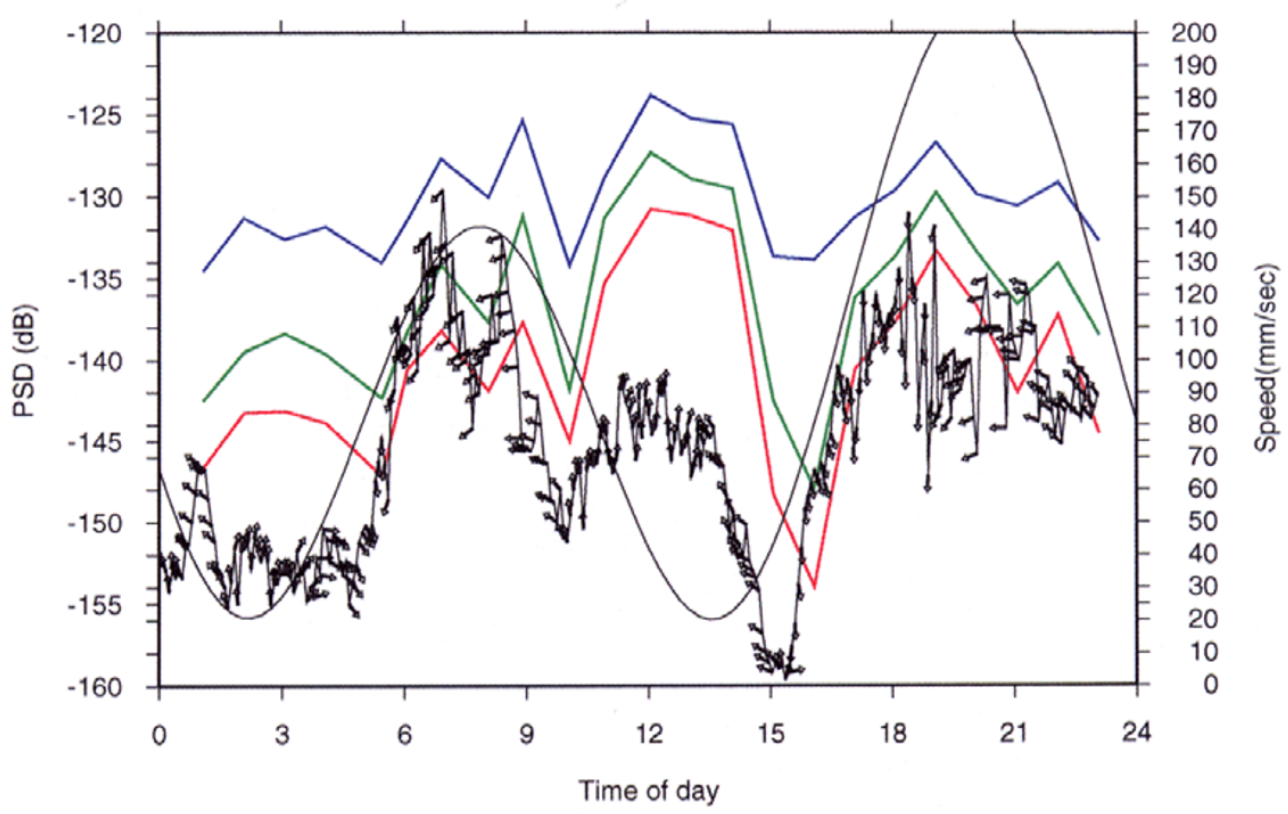

Fig. 8. Fluctuations as a function of time of day (on 09/01/97) of bottom current velocity (black) and direction (arrows, north is towards top of figure) compared to those of MOIS vertical component noise power spectral density in the period ranges 10-20 sec (red), 20-30 sec (blue) and 30-50 sec (green). Power spectral density (PSD) scale is on the left and velocity scale on the right. Noise PSD has been computed every hour using intervals of one hour of data. The smooth solid line corresponds to the theoretical solid tide computed for the location of the MOIS station (the scale spans from -100 to +100 microgals).

MOIS Aug $10,1997,10$ to 50 sec $\mathrm{BHZ}$

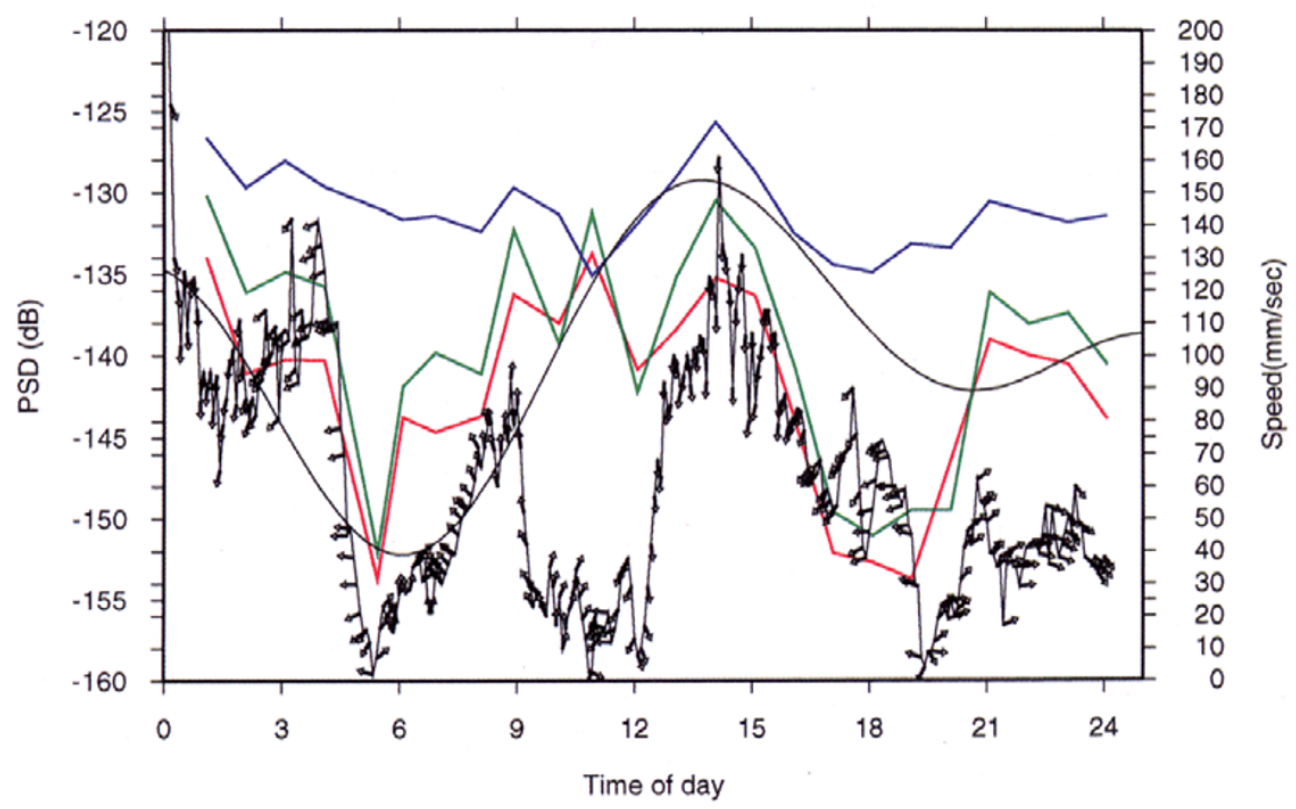

Fig. 9. Same as Fig. 8 on August 10, 1998. The increase in power spectral density around 10:30 am UTC coincides with the arrival of surface waves from an Ms 6.0 earthquake in western Australia. 


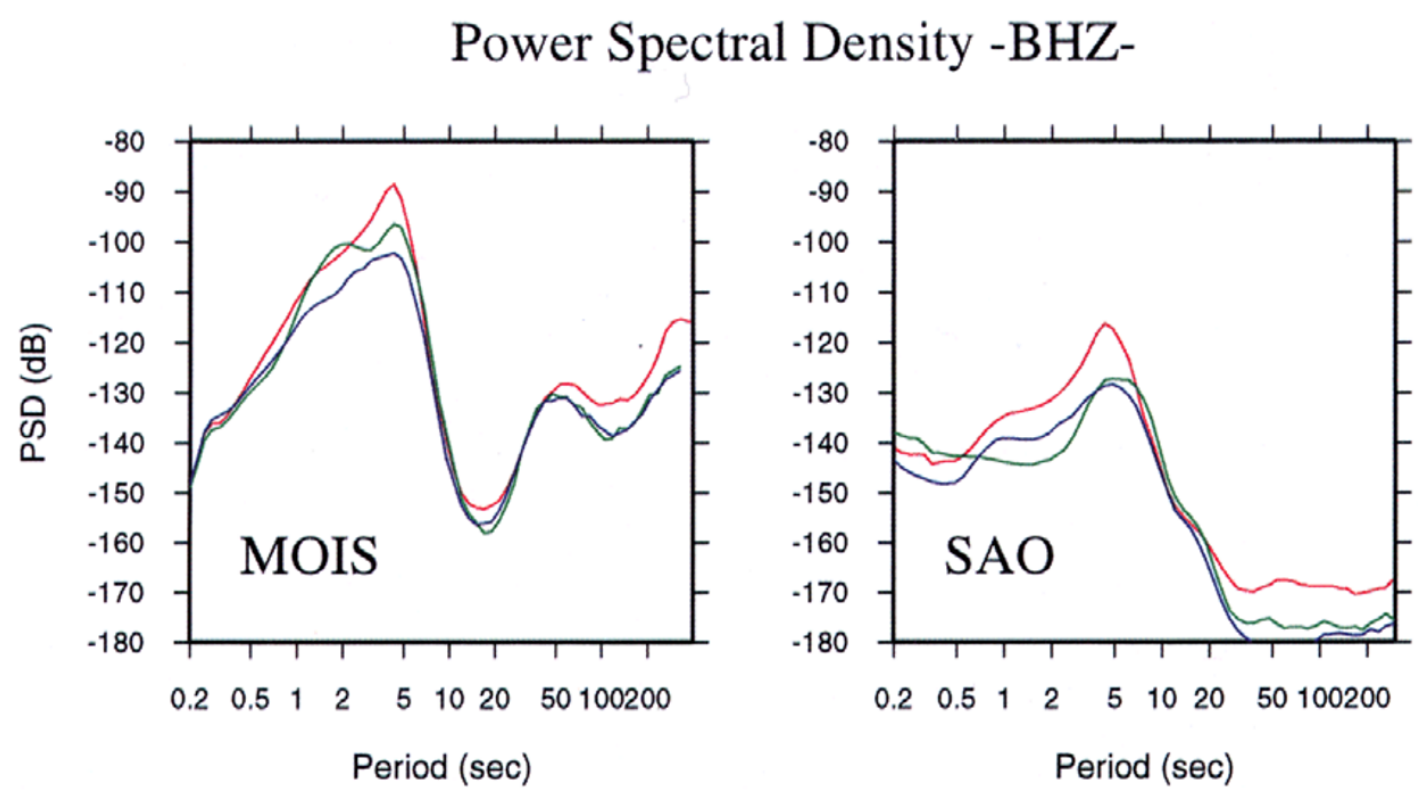

Fig. 10. Comparison of PSD of seismic noise on the vertical component (BHZ) at SAO and MOIS at 3 epochs during the experiment: July 11 (15:00h, red), August 18 (18:00h, green), and September 1 (16:00h, blue), 1997. The spectra have been computed using one hour samples corresponding to time intervals of lowest noise on each of the days considered for MOIS

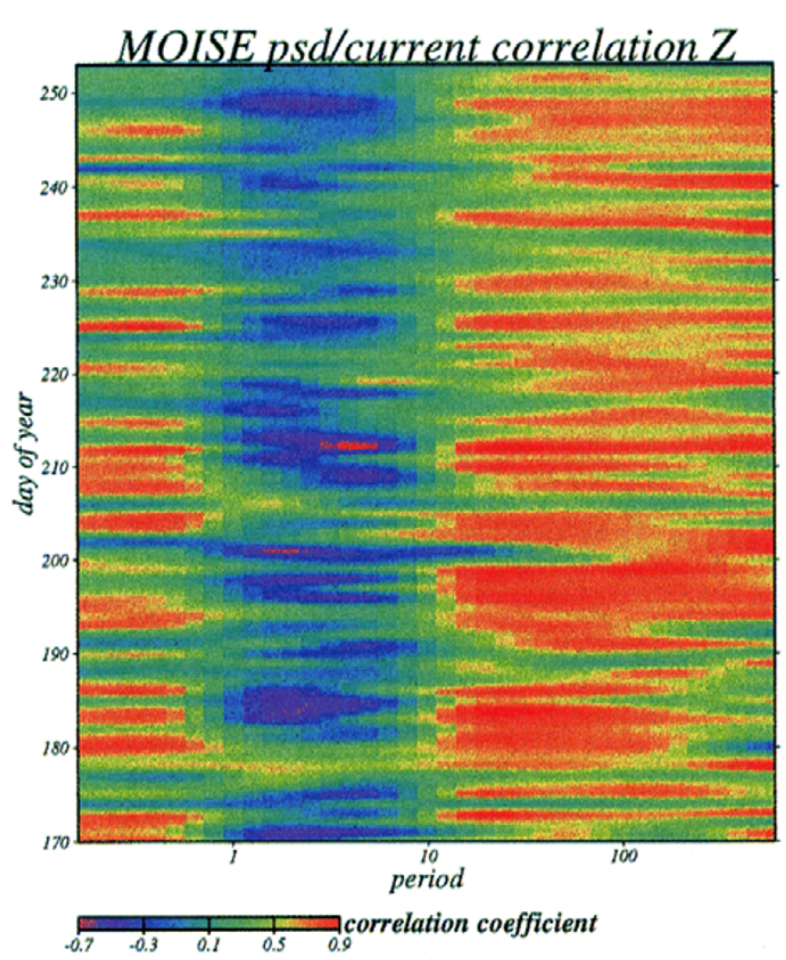

(a)

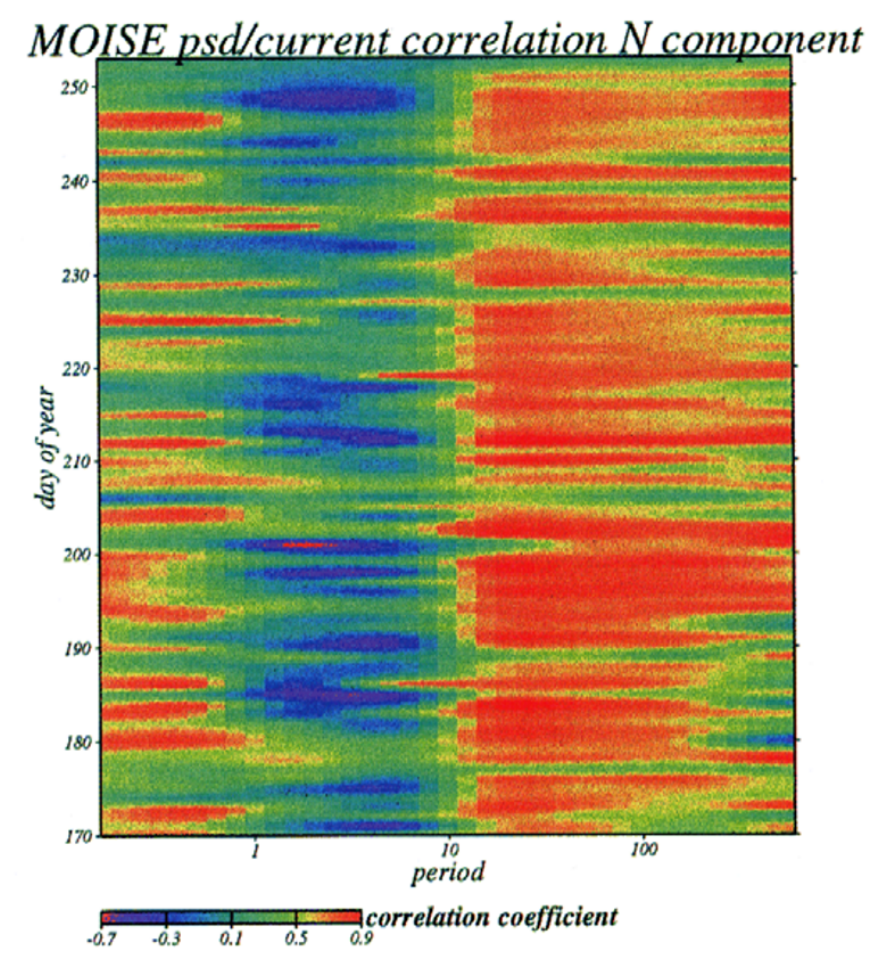

(b)

Fig. 11. Correlation of current velocity and power-spectral-density (PSD) of vertical (a) and north (b) component at MOIS site as a function of time and period. Noise PSD spectra were computed over the entire frequency band using samples of one hour length, centered on every hour, and the correlation coefficient was calculated for each 24 hour period, using hourly samples of current velocity and PSD. High correlation is observed on both sides of the microseismic peak for both vertical and horizontal components. Low correlation can sometimes, although not systematically, be associated with times of occurrence of large regional $(\mathrm{M}>4.5)$ or teleseismic $(\mathrm{Ms}>6.0)$ earthquakes. Such is the case, for example on day 207. 
period - a period appropriate for observations of teleseismic long period body waves and regional surface waves - appears to be comparable to that observed at nearby continental sites. This indicates to us that, at least in the long period band, proper installation in the relatively soft ocean-floor sediment, with the instrument completely buried and shielded from currents would likely result in a site quality comparable to that achieved on average on land sites (e.g. Sutton and Duennebier, 1988; Duennebier and Sutton, 1995). This conclusion is in agreement with that reached during the OFM experiment, in which the ocean-bottom installed broadband seismic package was almost but not completely buried in the ground, however, it was protected from currents by a shield similar to that initially planned for the MOISE experiment (Beauduin et al., 1996).

Figure 10 compares noise levels on the vertical component at MOIS and SAO for three different epochs during the experiment. In addition to fluctuations at periods longer than the microseismic peak, as previously described, we note variations in the noise in the microseismic band that appear to be in phase between the two stations, but with higher levels of noise on the ocean floor (by $20 \mathrm{~dB}$ on the vertical component). Noise in this period band has been documented to be strongly correlated with weather patterns (e.g. Webb, 1997) which should affect the ocean bottom station and near by land stations in similar ways. At the shortest periods analyzed $(1-5 \mathrm{~Hz})$ noise at MOIS appears to be more stable than at SAO, which explains the high quality of the short-period filtered MOIS records obtained for the regional event shown in Fig. 5. At periods shorter than $1 \mathrm{~s}$, there appears to be again periods of high correlation of the MOIS background noise with the bottom current, in agreement with previous results from pressure gauge deployments (Webb, 1988, 1991). Figures 11(a) and (b) show spectrograms of the correlation of power spectral density (vertical and north component respectively) with the bottom current velocity. During many days, the correlation on both sides of the microseismic peak reached values in excess of 0.9 . Unfortunately, it was not possible to take advantage of this observation and subtract the current-correlated signal from the seismic data in the long period band of interest for earthquake observations (10-50 sec), because the sampling rate of $300 \mathrm{sec}$ of the current-meter data was insufficient. The correlation with current velocity notably persists at low frequency beyond the "low-noise notch". Infragravity waves are thought to be the main cause of rising levels of noise at periods larger than $50 \mathrm{~s}$ in deep ocean pressure measurements (Webb et al., 1991). During the intervals of time when the correlation of MOIS noise with bottom current is not strong, such infragravity waves may be a dominant cause of noise down to periods of $30 \mathrm{~s}$, given the relatively shallow location of the seismic package. This could explain the relatively narrow "low noise notch" in the MOISE data (e.g. Orcutt et al., 1993), as compared to data from differential pressure gauges in the deep ocean (e.g. Beauduin et $a l ., 1996)$. The daily noise fluctuations at periods longer than $10 \mathrm{sec}$ present some coherency between the MOIS site and the nearby land sites, indicative of a complex regional interaction of tides, currents and atmospheric disturbances.

\section{Conclusions}

Through the acquisition of 3 months of continuous three component broadband seismic data in Monterey Bay, the MOISE experiment has demonstrated the feasibility of deployment of long term autonomous broadband seismic packages on the ocean floor using ROV technology and the usefulness of auxiliary instrumentation, particularly currentmeters, to understand the sources of background noise. It was indeed found that, apart from the microseismic peak frequency band, the background noise on all three components was highly correlated with current velocity. At frequencies higher than $1 \mathrm{~Hz}$, noise levels were comparable to or lower than those recorded on land stations. The microseismic peak level was $20 \mathrm{~dB}$ higher than on nearby land stations, comparable on all three components. The low noise "notch" at periods between 10-30 sec was particularly marked on the vertical component, where, during quiet periods, noise levels were comparable to those at the nearby SAO land station on noisy days, providing acceptable intermediate frequency recordings of several regional and teleseismic events. These results indicate that proper installation with the seismometer package entirely buried in the sediment should have provided data of quality comparable to that achieved at near-coastal land stations, on both sides of the micro-seismic peak.

Acknowledgments. We owe the success of the MOISE experiment to the outstanding efforts of the technical team, which also included Jean-Claude Koenig, Jean Savary at DT/INSU, Paul McGill and Craig Dawe at MBARI. Karen Salamy at MBARI assisted with video and various preparation and data processing aspects of the experiment. B. Romanowicz thanks L. Breger, K. Galdamez, L. Gee, C. Megnin at UC Berkeley and P. McGill at MBARI for help with graphics. J. Orcutt provided valuable comments on the draft manuscript. We also thank 2 anonymous reviewers for their constructive comments. This is Berkeley Seismological Laboratory contribution number 9807.

\section{References}

Beauduin, R., J.-P. Montagner, and J.-F. Karczewski, Time evolution of broadband seismic noise during the French Pilot experiment OFM/SISMOBS, Geophys. Res. Lett., 23, 2995-2998, 1996.

COSOD II, Rep. 2nd Conf. Sci. Ocean Drilling, Strasbourg, France, (European Science Foundation), 1987

Duennebier, F. K. and G. H. Sutton, Fidelity of ocean bottom seismic observations, Marine Geophys. Res., 17, 535-555, 1995.

Forsyth, D., A. Dziewonski, and B. Romanowicz, Scientific objectives and required instrumentation, in Proceedings of Ocean Seismic Network Workshop: Broadband Seismology in the Oceans: Towards a Five Year Plan, pp. 8-18, 1995.

Montagner, J. P. and Y. Lancelot (eds.), Multidisciplinary observatories on the deep seafloor, in Report of International Ocean Network Workshop Held at Marseille, France, 01/11-01/13, 1995, INSU/CNRS, IFREMER, ODP-France, 1995.

Montagner, J. P., B. Romanowicz, and J. F. Karczewski, A first step toward an oceanic geophysical observatory, EOS Trans. $A G U, 75,150-151,1994$ a.

Montagner, J. P., J. F. Karczewski, B. Romanowicz, S. Bouaricha, P. Lognonne, G. Roult, E. Stutzmann, J. L. Thirot, J. Brion, B. Dole, D. Fouassier, J.-C. Koenig, J. C. Savary, L. Floury, J. Dupond, A. Echardour, and H. Floc'h, The french pilot experiment OFM-SISMOBS: first scientific results on noise level and event detection, Phys. Earth Planet. Inter., 84, 321-336, 1994b.

Montagner, J. P., P. Tarits, E. Stutzmann, J. L. Thirot, D. Stakes, B. Romanowicz, J. F. Karczewski, A. Dubreule, S. Etchemendy, K. Salamy, and D. Neuhauser, Preliminary results on the intercomparison of seismic and electromagnetic data from the MOISE experiment, EOS Trans. $A G U$, 78, F461, 1997.

Orcutt, J. A. and R. A. Stephen, OSN seismograph system is underway, Seismic Waves, OSN Newsletter, JOI, Inc., Washington, 2, 3-5, 1993. 
Orcutt, J. A., C. S. Cox, A. C. Kibblewhite, W. A. Kuperman, and H. Schmidt, Observations and causes of ocean and seafloor noise at ultralow and very-low frequencies, in Natural Physical Sources of Underwater Sound, edited by B. R. Kerman, pp. 203-232, 1993.

Peterson, J. R., Observations and modeling of seismic background noise, U.S. Geological Survey Open File Report, 93-322, 94 pp., 1993.

Purdy, M. (ed.), Broadband Seismology in the Oceans: towards a five year plan, in Report of Ocean Seismic Network Workshop, Joint Oceanographic Institutions, 1995.

Purdy, G. M. and A. M. Dziewonski, Proc. Workshop on Broad-Band Downhole Seismometers in the Deep Ocean, Woods Hole, MA, Apr. 26-28, 1988, Joint Oceanogr. Inst. and U.S. Sci. Advisory Comm., 1989.

Romanowicz, B. and A. M. Dziewonski, Towards a federation of broadband seismic networks, EOS Trans. AGU, 67, 541-542, 1986.

Romanowicz, B., J. F. Karczewski, M. Cara, P. Bernard, J. Borsenberger, B. Dole, D. Fouassier, J. C. Koenig, M. Morand, R. Pillet, A. Pyrolley, and D. Rouland, The Geoscope program: present status and perspectives, Bull. Seism. Soc. Am., 81, 243-264, 1991.

Romanowicz, B., D. Stakes, J. P. Montagner, R. Uhrhammer, M. Begnaud, E. Stutzmann, and M. Pasyanos, First results of data analysis from the MOISE experiment, EOS Trans. AGU, 78, F461, 1997.

Stakes, D., B. Romanowicz, J. P. Montagner, P. Tarits, J. F. Karczewski, S. Etchemendy, P. McGill, D. Neuhauser, J.-C. Koenig, and J. Savary, The 1997 MOISE experiment at Monterey Bay, CA, EOS Trans. $A G U, \mathbf{7 8 ,}$ F461, 1997.

Stakes, D., B. Romanowicz, J. P. Montagner, P. Tarits, J. F. Karczewski,
S. Etchemendy, D. Neuhauser, P. McGill, J.-C. Koenig, J. Savary, M. Begnaud, and M. Pasyanos, MOISE: Monterey Bay Ocean Bottom International Seismic Experiment, EOS Trans. AGU, 79, 301-309, 1998.

Sutton, G. H. and N. Barstow, Ocean-bottom ultralowfrequency (ULF) seismo-acoustic ambient noise: 0.002 to $0.4 \mathrm{~Hz}$, J. Acoust. Soc. Am., 87, 2005-2012, 1990.

Sutton, G. and F. Duennebier, Optimum design of ocean-bottom seismometers, Mar. Geophys. Res., 9, 47-65, 1988.

Suyehiro, K., T. Kanazawa, N. Hirata, M. Shinohara, and H. Kinoshita, Broadband downhole digital seismometer experiment at site 794, Proc. O.D.P. 127/128, 1061-1073, 1992.

Suyehiro, K., J. P. Montagner, A. M. Dziewonski, and B. Romanowicz, The International Ocean Network Structure, in Proceedings ION/ODP International Workshop, Multidisciplinary Observatories on the Deep Seafloor, Marseille, pp. 61-72, 1995.

Webb, S. C., Long period acoustic and seismic measurements and ocean floor currents, IEEE, J. Oceanic Eng., 13, 263-270, 1988.

Webb, S. C., Broadband seismology and noise under the ocean, Rev. Geophys. Space Phys., 36, 105-142, 1997.

Webb, S. C., X. Zhang, and W. Crawford, Infragravity waves in the deep ocean, J. Geophys. Res., 96, 2723-2736, 1991.

B. Romanowicz (e-mail: barbara@seismo.berkeley.edu), D. Stakes, J. P. Montagner, P. Tarits, R. Uhrhammer, M. Begnaud, E. Stutzmann, M. Pasyanos, J.-F. Karczewski, S. Etchemendy, and D. Neuhauser 